Paper ID \#20066

\title{
100 Percent Renewable Energy for Pennsylvania via Solar, Wind, and Water
}

\section{Dr. Rajarajan Subramanian, Pennsylvania State University, Harrisburg}

For more than 25 years, Dr. Rajarajan Subramanian has worked in government, industry and education. He earned his B.E in 1982 from Annamalai University, India. He earned his Ph.D. and master's degree in Civil Engineering from the Department of Civil \& Costal Engineering, University of Florida. He is a member of many professional committees and several professional societies. His areas of specialization include Portland Cement Concrete, Asphalt Cement Concrete, Sustainable Energy in Buildings and Roads and Construction Project Management. Currently, he is teaching Civil and Construction Engineering at Pennsylvania State University at Harrisburg, Pennsylvania.

\section{Dr. Fazil T. Najafi, University of Florida}

\section{Dr. Fazil T. Najafi}

For more than forty years, Dr. Fazil T. Najafi has worked in government, industry and education. He earned a BSCE in 1963 from the American College of Engineering, in his place of birth, Kabul, Afghanistan, and since then came to the United States with a Fulbright scholarship earning his MS in civil engineering in 1972 and a Ph.D. degree in transportation in 1977. His experience in industry includes work as a highway, structural, mechanical, and consultant engineer and construction manager for government groups and private companies. Najafi went on to teaching, first becoming an assistant professor at Villanova University, Pennsylvania in 1977, a visiting professor at George Mason University, and then to the University of Florida, Department of Civil Engineering, where he advanced to associate professor in 1991 and then full professor in 2000 in the Department of Civil and Coastal Engineering. He has received numerous awards including a scholarship award (Fulbright), teaching awards, best paper awards, community service awards, and admitted as an Eminent Engineer into Tau Beta Pi. His research on passive radon-resistant new residential building construction was adapted in HB1647 building code of Florida Legislature. Najafi is a member of numerous professional societies and has served on many committees and programs, and continuously attends and presents refereed papers at international, national, and local professional meetings and conferences. Lastly, Najafi attends courses, seminars and workshops, and has developed courses, videos and software packages during his career. His areas of specialization include transportation planning and management, legal aspects, construction contract administration, renewable energy, and public works. 


\title{
$100 \%$ Renewable energy for Pennsylvania via Solar, Wind, Water \\ and
}

STEM Education

\begin{abstract}
The growing energy crisis all over the world forced us to seek for alternative forms of energy such as solar, wind and water (Hydro power). Each and every state in the United States strives to make it possible to introduce some sort of renewable energy via either solar, wind or water driven methods. The primary objective of this study is to determine the feasibility of converting the state of Pennsylvania's energy production to $100 \%$ renewable using cutting edge technology that exists today. The scope of the study will include reviewing the current status of renewable energy within the state, the current projections for Pennsylvania's future renewable energy production, and proposing a plan for creating a reliance on renewable energy. There is a broad review of how all the utilities in the state produce their power, as well as a review of the current literature and journals about the future of Pennsylvania's renewable energy front. In addition, a review of The Solutions Project will be done to determine whether or not the plan they put forth for the state of Pennsylvania is applicable, with a review of the feasibility and success of analogous projects like Germany's government backed solar incentives.

Also, there is a need for attracting younger generation towards Science, Technology, Engineering, and Mathematics (STEM) field as United States is in shortage of engineers and scientists. The renewable energy is one of the areas where lot of engineers and scientists are going to be employed in the future. It can be emphasized that STEM workforce plays important role for Pennsylvania to achieve 100\% renewable energy. In academia, a lot of emphasis should be given on including the aspects of renewable energy into the engineering curriculum.
\end{abstract}

\section{Keywords}

Solar energy, Cost-Effectiveness of Photovoltaic, Solutions Project, Wind Energy, STEM 


\section{Introduction}

Energy consumption (as of 2015) in the United States has almost tripled comparing to the consumption recorded in 1950. In 2015, the energy consumption has rocketed to 97.3 trillion BTUs. From the history of usage of energy in U.S.A, it is clear that energy consumption is going up endlessly.

Use of "renewable energy" is reducing the threat of climate change and making the air safer to breathe by powering millions of homes and businesses. Nationwide, our landscape has changed to include more wind farms and rooftop solar panels that have become a familiar part of our life. But, still the full range of clean energy alternatives are yet to be mined. The Chinese and Indian leaders are also turning to wind and solar power to reduce climate change pollution and sustain economic growth. National Resources Defense Council of U.S.A (NRDC) is an organization that supports to safeguard United States' natural resources from destruction in the name of "Energy Production".

NRDC works to safeguard the earth-its people, its plants and animals, and the natural systems on which all life depends. Also, it supports the Chinese Government for the development of a flexible power grid capable of handling a high penetration of renewable energy, and it promotes policies that help utilities manage that new influx. In India, NRDC advises government officials on meeting the nation's solar energy and wind goals and adopting financial structures that encourage clean energy projects. And in Latin America, NRDC works with local partners to encourage governments to focus on developing their renewable sectors instead of continuing to rely on fossil fuels [1].

\section{Pennsylvania Energy Production and Consumption}

It is rational to review the current state of Pennsylvania's energy production prior to thinking about how to improve Pennsylvania's renewable energy production. As per the United States Energy Information Administration, Pennsylvania used 3,902 trillion British Thermal Units (BTUs) of energy in 2014 after Texas, California, Louisiana, Florida, and Illinois in energy usage across the United States Per the United States Energy [1]. This statistic alone shows how important energy production is to the state of Pennsylvania. The energy production statistic covers residential homes, commercial businesses, industrial production, and transportation. The breakdown of energy consumption can be seen in Table 1 below. About 25\% of Pennsylvania's energy consumption is attributed to Transportation sector. However, for the purposes of this paper we are not going to account for methods of improvement in the transportation industry. This allows the paper to focus on the energy consumption of homes and businesses that rely on the energy produced by the power utilities across the state. 
Table 1. Consumption by End Use Sector (2016)

\begin{tabular}{|ccc|} 
Method & $\begin{array}{c}\text { Pennsylvania (trillion } \\
\text { BTUs) }\end{array}$ & Share of U.S. \\
\hline Residential & 972 & $4.5 \%$ \\
\hline Commercial & 653 & $3.6 \%$ \\
\hline Industrial & 1375 & $4.3 \%$ \\
\hline Transportation & 903 & $3.3 \%$ \\
\hline
\end{tabular}

Table 2 shows the percentage of electricity generated in each category while Figure 1 shows the consumption of electricity in each respective category [2]. Table 2 shows that Pennsylvania is heavily dependent on Nuclear based power plants to generate electricity, representing 40.8 percent of Pennsylvania's total power production. The second largest method of electricity generation for Pennsylvania is Natural gas -Fired power plants at 33.1 percent. Third largest sector that produces 21.6 percent electricity is the Coal-fired power stations. This shows that fossil fuel or non-renewable mechanisms account for approximately 55 percent of Pennsylvania's total energy production. The United States average for fossil fuel usage is approximately 65 percent. Nuclear power, accounting for $40.8 \%$ of Pennsylvania's total, is contested as non-renewable but produces considerably less carbon dioxide than natural gas and coal-fired plants. Ultimately the problem of fuel mining, fuel processing and fuel storage makes nuclear power a viable option for a time but it is exhaustible. The intrinsic problems of nuclear waste mitigation and storage implies that Nuclear Fission plants cannot satisfy the growing power demand issue on a national or state-wide scale. Pennsylvania is behind the rest of the United States when it comes to non-fossil fuel energy production. It is recommended that Pennsylvania, as the sixth largest energy consumer in the US, needs to change its energy plan quickly. Pennsylvania utilities provided by private and public sectors should redirect their focus to renewable energies such as Solar Photovoltaic (PV), Concentrated Solar Power (CSP), and On/Offshore Wind-Turbine to solve the growing power demand issues.

Table 2. Net Electricity Generation for State of Pennsylvania (October 2016)

\begin{tabular}{|ccc|}
\hline Method & Pennsylvania & U.S. Average \\
\hline Petroleum-Fired & $0.1 \%$ & $0.3 \%$ \\
\hline Natural Gas-Fired & $33.1 \%$ & $32.8 \%$ \\
\hline Coal-Fired & $21.6 \%$ & $31.8 \%$ \\
\hline Nuclear & $40.8 \%$ & $19.4 \%$ \\
\hline Other Renewables & $4.1 \%$ & $15.1 \%$ \\
\hline
\end{tabular}




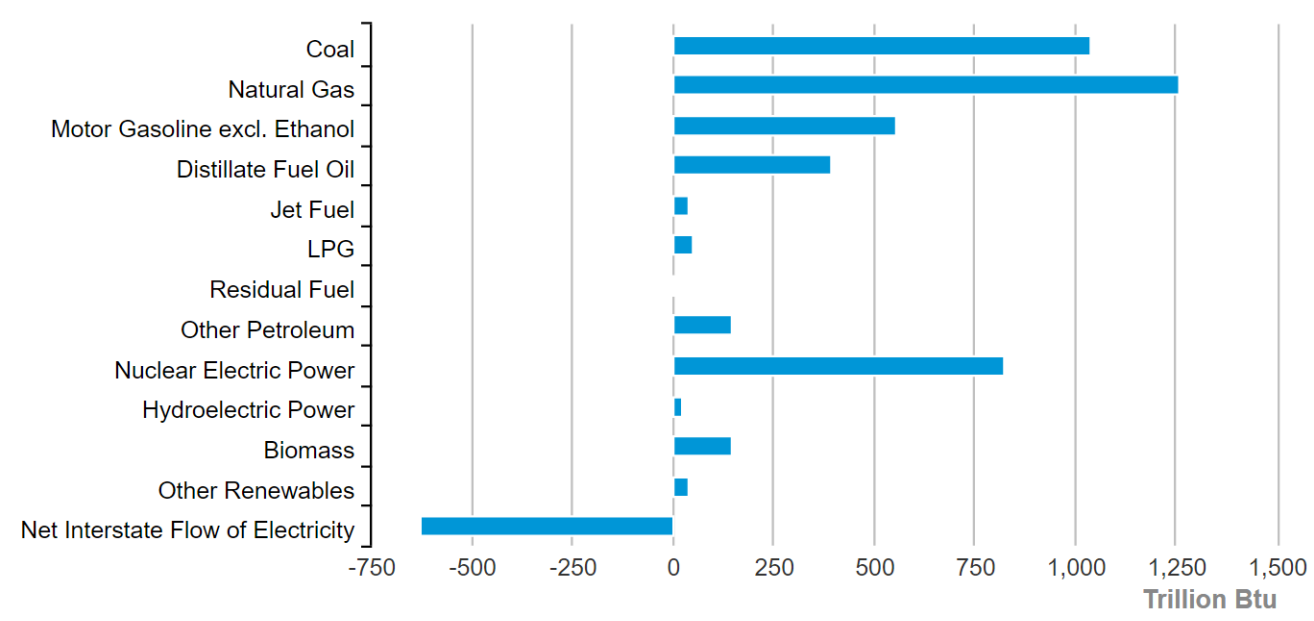

eia Source: Energy Information Administration, State Energy Data System

Figure 1. Pennsylvania Energy Consumption Estimates (2014)

Pennsylvania Quick Facts on Energy use:

- Pennsylvania's annual gross natural gas production, primarily from the Marcellus Shale, exceeded 4 trillion cubic feet in 2014, doubling the state's 2012 production and making Pennsylvania the nation's second-largest natural gas producer.

- Pennsylvania was the fourth-largest coal-producing state in the nation in 2014 and the only state producing anthracite coal, which has a higher heat value than other kinds of coal.

- In 2015, Pennsylvania ranked second in the nation in electricity generation from nuclear power. The state obtained $40.8 \%$ of its net electricity generation from nuclear power, more than from any other source.

- Pennsylvania's Alternative Energy Portfolio Standards require $18 \%$ of electricity sold by 2021 to come from approved renewable or alternative sources, including at least $0.5 \%$ solar photovoltaic power. In 2015, renewable energy accounted for $4 \%$ of Pennsylvania's net electricity generation.

- As of 2014, 51\% of Pennsylvania households used natural gas as their primary home heating fuel, while $21 \%$ depended on electricity for heat and $19 \%$ relied on fuel oil. Other heating fuels used in the state included propane, wood, and coal [1].

There are 10 major investors owned power companies in Pennsylvania and several non-investor owned utility companies. These companies serve approximately 12.8 million residents across the state. The cost of these utilities ranges from 14.40 cents per kilowatt-hour from Residential sector to 6.85 cents per kilowatt-hour for Industrial sector USA as far as the electrical energy consumptions are concerned [3]. The four major companies rely heavily on fossil fuels and nuclear technology for energy production with most the energy coming from nuclear, coal and natural gas. In order for Pennsylvania to make the switch to renewable energy sources, the economic feasibility for these companies to make the change must be ensured. 
Pennsylvania, like many states in the Mid-Atlantic region of the United States, has abundant sunshine which makes it a great location to install solar power. Pennsylvania solar installers are among the busiest in the country and the state ranked sixth in the country for solar PV installations in 2011 according to the Solar Energy Industries Association with 88 megawatts. As of 2011 Pennsylvania had installed more than 141 megawatts of solar power ranking it eighth amongst US states.

Great incentives and rebates are available to home owners and businesses for Pennsylvania solar installation. For example, the state offers solar rebates of up to 35 percent of the installed cost of solar [4].

\section{State Policies}

\section{Renewable Portfolio Standards (RPS)}

The generation of electricity from renewables has increased in part because of the effects of state-based policies adopted during the restructuring of many domestic electricity markets. One prominent policy mechanism for increasing the level of renewable electricity generation is the renewables portfolio standard (RPS), also known as the renewable energy standard. Typically, an RPS requires a specific percentage as the minimum share of the electricity produced (or sold) in a state that must be generated by some collection of eligible renewable technologies. The policies vary in a number of ways, such as the sources of renewables included; the form, timeline, and stringencies of the numerical goals; the extent to which utility scale and end-use types of renewables are specified; and whether the goals include separate targets for particular renewable technologies.

As of 2008, 27 states and the District of Columba had RPSs, and another 6 states had voluntary programs (Figure 2). It is estimated that full compliance with those RPSs will require an additional $60 \mathrm{GW}$ of new renewable electricity capacity by 2025 . The actual RPS mandates vary from state to state. Maryland's RPS, for example, requires 9.5 percent renewable electricity by 2022, whereas California's requires 20 percent by 2010. Pennsylvania's RPS is expected to be at 18 for the year 2020. Right now, Pennsylvania achieved only $4 \%$ renewable energy production. Therefore, it is very unlikely that Pennsylvania will achieve $18 \%$ in three years.

One element that varies among different standards is how each standard applies to specific sources of renewable energy. Figure 2 shows the RPSs with specific requirements for electricity generation from solar and other distributed renewable resources [5]. 


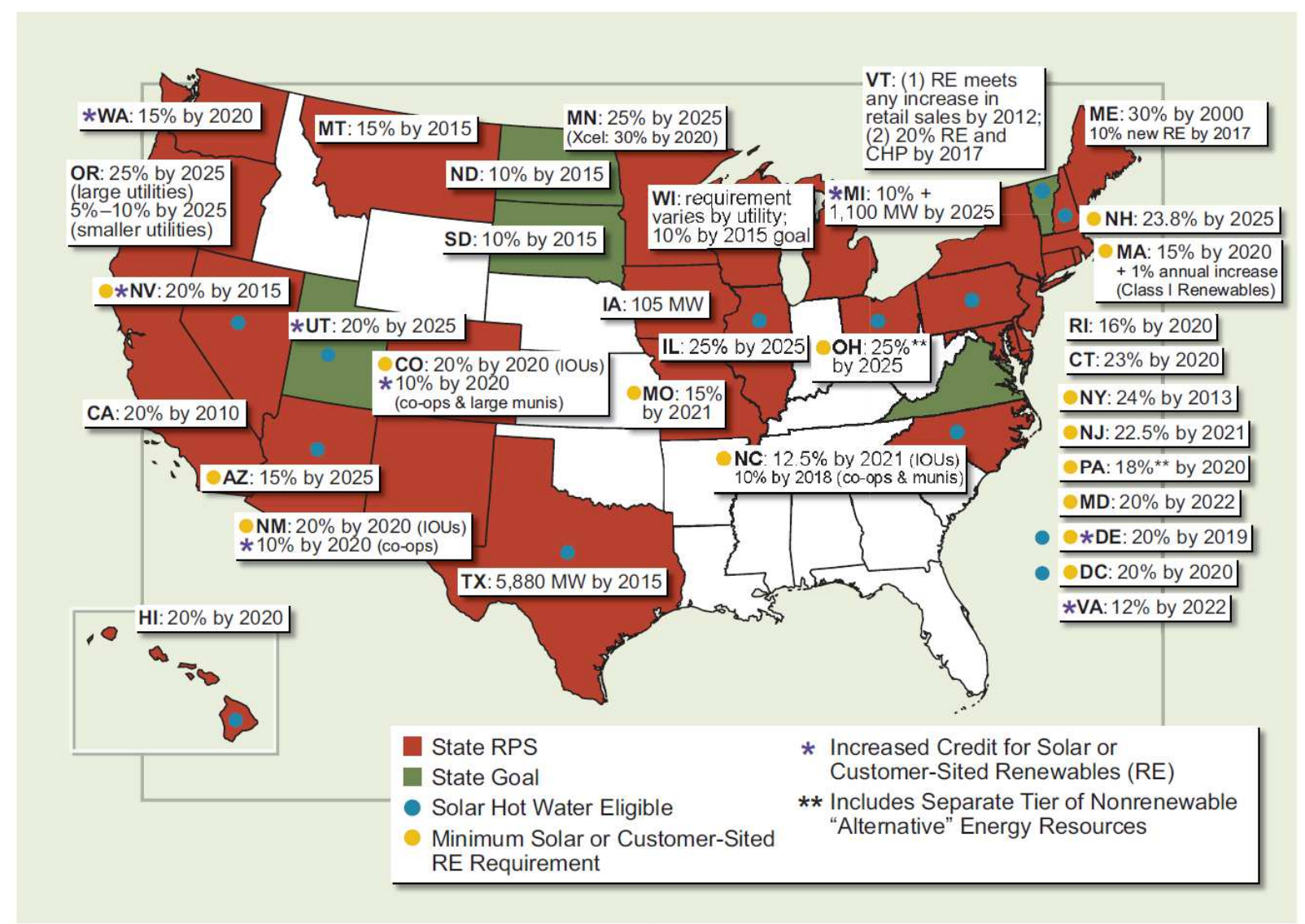

Figure 2 Map of state renewable portfolio standards

Pennsylvania's current renewable energy production is only 4 percent of Pennsylvania's total energy production. The main source of renewable energy production is related to solar power Photovoltaics. There are currently more than 15 commercial solar energy production facilities across the state. The 223 megawatts of solar energy currently installed in Pennsylvania ranks the state 12th in the country for installed solar capacity [6]. There is enough solar energy installed in the state to power 25,600 homes. However, Pennsylvania ranks third in the nation as potential solar power producer [6]. The large gap between installed and estimated total capacity suggests that there is significant room for improvement for Pennsylvania in the solar energy field. Other nations have already begun to supplement their growing energy demands with renewable means such as PV and CSP. A comparison of the solar radiation exposure for Germany and the USA is found below [8]. 


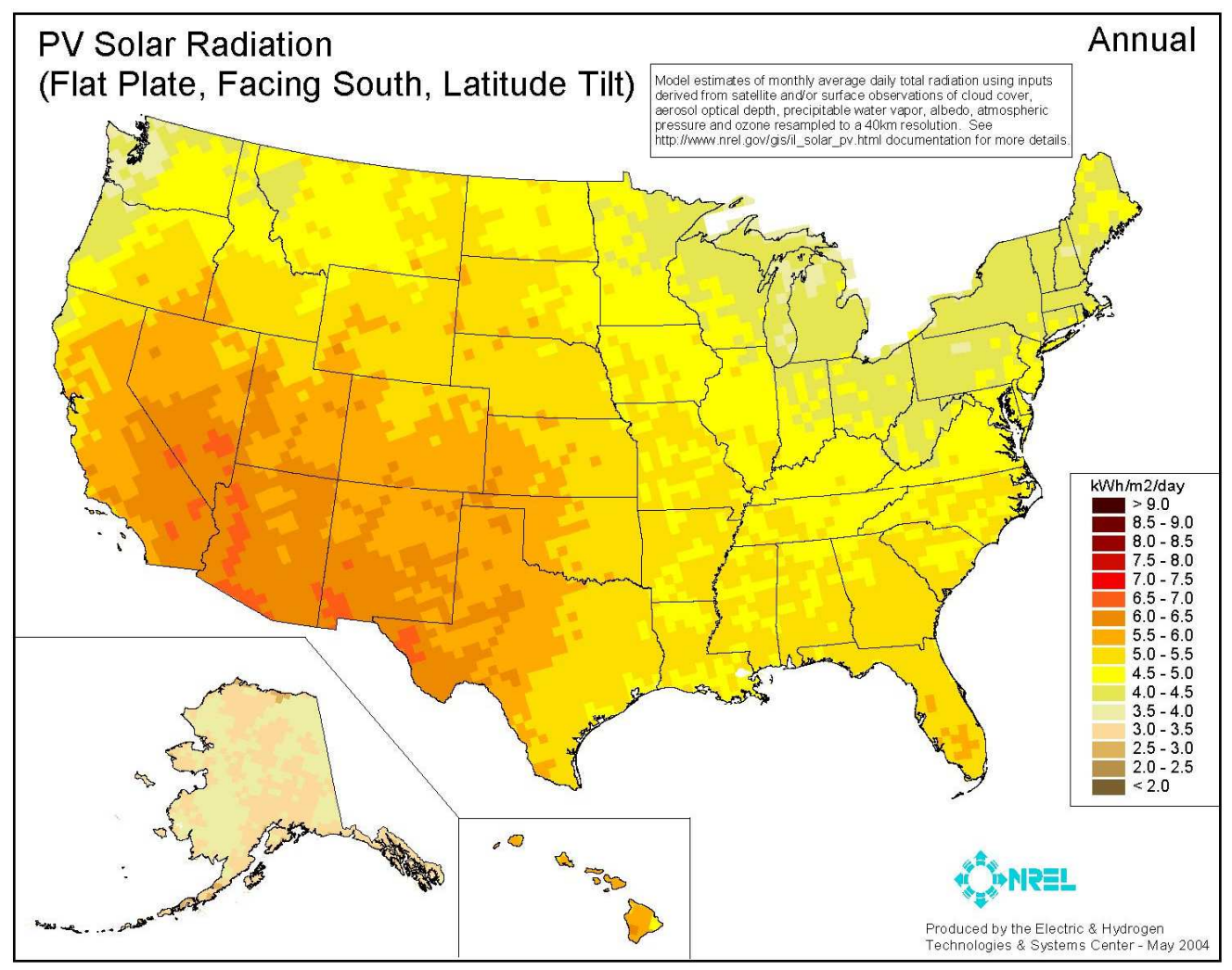

Figure 3. U.S.A Solar Exposure Indexes

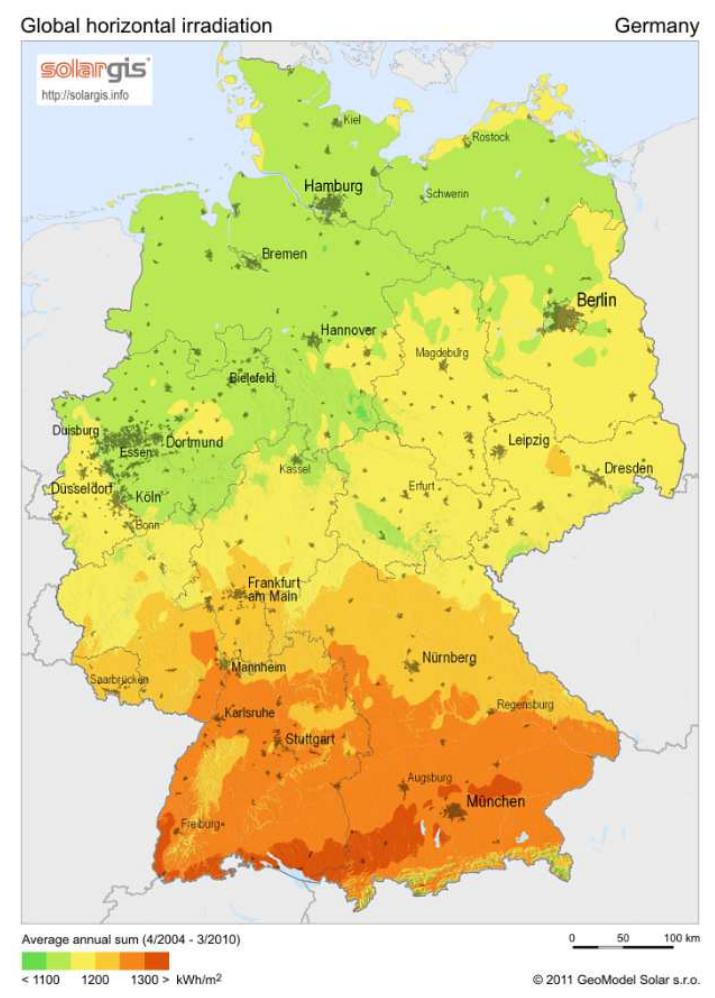

Figure 4. Germany Solar Exposure Indexes 
As Figures 3 and 4 show, the USA receives a significantly higher amount of solar radiation than Germany. This is important when noting what percentage of these nations' energy come from solar. The Center for Climate and Energy Solutions estimates that solar power accounts for only $0.2 \%$ of total energy production in the United States [11]. The USA's total solar capacity was estimated at $15.9 \mathrm{GW}$ at the end of 2013 . Germany has roughly $36 \mathrm{GW}$ of solar capacity installed but due to its poor solar exposure, it generally accounts for only $2 \%$ of its total energy production. However, on peek exposure days Germany can generate a significant portion of its energy demands. On June $9^{\text {th }} 2014$ Germany broke its old record by producing approximately 23 GW of solar power which is more than $50 \%$ of its energy demand rate on that day [8]. The figures and statistics above indicate that other nations are dedicated to the idea of renewable energy. Germany's success in creating a solar PV industry where the climate is far from optimal can serve to support the feasibility of large scale solar energy in Pennsylvania.

The state's current energy plan is not sustainable and Pennsylvania is running out of its current method of coal energy production at a faster rate than the rest of the United States because of regular and faster consumption [15]. If a change is not made soon, the continual strain on nonrenewable sources will likely drive the price of energy up and force utilities to look for alternative power sources. Pennsylvania ranks among the highest in the nation for its potential to use renewable energy, particularly solar. Instead of waiting for energy issues to manifest as utility pricing issues or fuel shortages, Pennsylvania should exercise prudence by investing in renewables and reducing dependence on fossil fuels.

\section{Pennsylvania's Future Renewable Production Plans}

From the $100 \%$ Pennsylvania website [13], it is learned by 2050 the state will produce $68.8 \%$ of electricity from Solar PV plants, 3.3\% from Residential rooftops PV, 2.4\% from Commercial/Government rooftop PV totaling to approximately $75 \%$. As mentioned earlier, solar energy is the state's most abundant and untapped energy resource. The Energy Information Administration (EIA) has estimated the state's solar potential at 3,000 gigawatts. [1]. The energy estimate is derived from the MW capacity as estimated by EIA and the average number of sunny days and hours of sun in a year from the National Oceanic and Atmospheric Administration (NOAA) data. Pennsylvania's total solar energy production capacity is larger than the state's total electricity consumption in 2010 . With roughly twenty times, the production capacity of the average usage, Pennsylvania has the potential to surpass its own energy needs. If Pennsylvania could reach even a fraction of its maximum solar potential, state utility companies could sell surplus energy to bordering states. Pennsylvania's solar energy production potential is so large that if utilized, it can have an impact on fossil fuel reliance in multiple states in the southeast region. Currently Pennsylvania's energy demands are so great that some utilities have to buy power from neighboring states where economically feasible.

Some companies are starting to see the great potential for solar energy production in Pennsylvania. In general, Pennsylvania has a considerable resource that remains, largely, untapped. Besides the creation of jobs and a new technical industry, increased renewable energy would lessen demand for foreign oil, keeping more money within the state and the country. The reduced pollution will benefit environmental and public health, saving residents money, and increasing the quality of life. 


\section{Solutions Project Plan for Pennsylvania's Future Sustainability}

This review of the solutions project is partly based on comparing the Solutions Project claims against other research and data. The feasibility of land usage for the project's various generation mechanisms is explored. Figure 5 shows the breakdown of various categories of renewable energy sources compared to their percentage of the proposed plan.

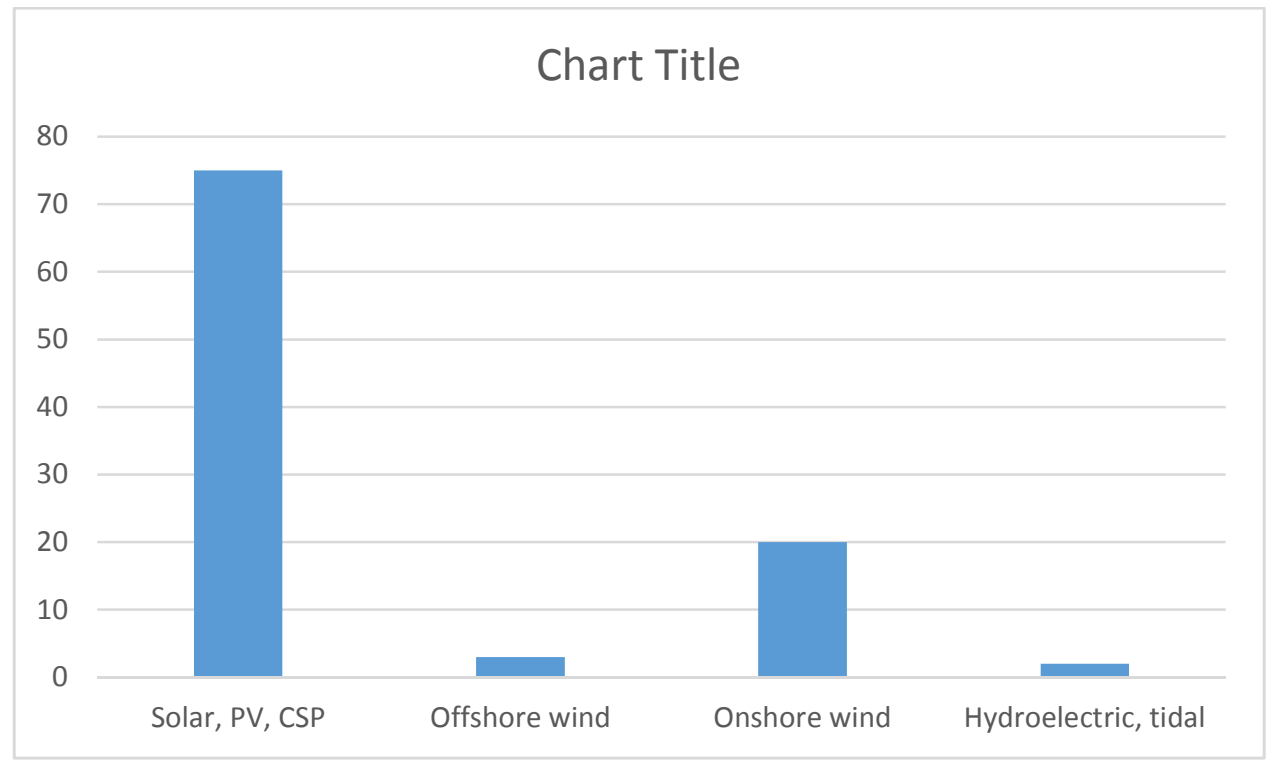

Figure 5. Categories of Renewable Energy Sources Breakdown

Solar PV and Concentrated Solar Power (CSP) makes up almost 75\% of the Solutions Project's plan for Pennsylvania. The PV portion is segregated into commercial and residential installations and large scale PV farms. It is estimated that Rooftop PV has the capacity to meet the power demand of Pennsylvania but the obvious problem of peak demand and energy storage remain. This indicates the Solar Rooftop PV alone could not only meet the proposed $75 \%$ of the Solutions Project plan but also account for a portion of the larger scale PV farms or CSP if needed [1].

The issue of how to acquire space for large scale Solar PV farms is a bit more complicated. It is ultimately up to the utilities to decide what spaces to use and how to acquire them. However, the amount of space proposed is $1.5 \%$ of the State's total land area. That is a significant figure when considering that production sites should be located close to points of use like cities to minimize transmission losses but spaced properly from living areas and between components.

The proposed contribution for wind energies stands around 23\% which would be a significant portion of the nearly $70 \mathrm{GW}$ of projected power demand. To analyze the probability of using wind energies we examined two more NREL studies about the wind energy onshore and the geography that makes offshore wind feasible. The NREL found that a significant portion of the east coast was very suitable for offshore wind. This is because the depth to foundation was approximately less than 30 meters. The south east and windier coast was less suitable having only a small amount of offshore space less than 100 meters to foundation. The north east coast closely matched the west coast being much more suitable for offshore wind generation. Georgia 
having comparable wind-speeds and depths to foundations had only a fraction of the square kilometers that Pennsylvania does and had an estimate of between 20-30 GW of capacity [6].

The conflicting ideas of how to implement wind energy in Pennsylvania is largely based on point of demand and transmission as well as projected energy consumption. Shallow offshore farms could generate a large portion of the state's power needs while taking up very little onshore area for transmission but the distance to transmit that power is considerable. Onshore wind requires a considerable amount of local land but may be closer to the point of use. Given the estimated offshore power capacity of Georgia and the considerably larger amount of offshore area in Pennsylvania, it is reasonable that most of the projected wind power could be generated offshore.

The $1 \%$ of waves devices proposed is largely the proof of concept or complimentary for the other forms of power and should only be used for optimal conditions. The cost-effectiveness of wave energy and system longevity is highly subjective and varied partly because the technology is somewhat emergent and not widely used.

\section{Masdar City and Germany}

Masdar City and Germany's government backed solar incentives are great examples of success in moving energy sector towards $100 \%$ renewable energy production. A review of the two is included to support the proposed Pennsylvania solution's feasibility. Masdar City was constructed in 2008, and was designed to be the Earth's most sustainable city. The city was designed to be $100 \%$ renewable, with zero carbon emissions and zero fossil fuel use. Masdar City has a $10 \mathrm{MW}$ solar PV plant that occupies about 210,000 $\mathrm{m}^{2}$. These solar panels help produce 17,500 megawatt-hours (MWh) of electricity and prevent 15,000 tons of carbon dioxide emissions annually [9]. The city also has strategies for water/wastewater and transportation to further their sustainability. The transportation system incorporates the use of electric cars, and even a driverless transit system which runs on a rail. All of the aforementioned technologies are in place to support the city's zero carbon emission efforts. Masdar City is still a work in progress, but it shows it is possible to reduce nonrenewable energy use dramatically. Not only does the city serve to test many renewable technologies, it also strives to integrate those technologies into the city's architecture and infrastructure as seamlessly as possible. The city is projected to house 40,000 people with another 50,000 possible commuters for a peak population of 90,000 [10]. Based on the statistics and results shown, Masdar City is a great example of people moving in the direction of $100 \%$ renewable energy use.

Germany has implemented a feed-in tariff with Germany's Renewable Energy Act. As a result, other countries are following, and Germany has become one of the top PV installers. Their incentive backed program encourages the use of renewable energy by offering to buy energy from solar installations like rooftop PV. Germany had a total of 30 terawatt-hours (TWh) of PV energy generated in 2013, which supported 5.7\% of the nation's net electricity consumption [13]. With this program in place costs of PV have decreased due to decreased capital costs and increased competition. The increase in PV installations has encouraged other renewable energy plants, such as wind, to increase their production as well. Germany has shown its commitment for $100 \%$ renewable energy by implementing these programs, and has had some success because of it. 
Other countries have followed Germany's lead and increased their renewable portfolios or plans as well. The University of Edinburgh recently published research that suggested using rooftop solar installations to help meet energy demands, renewable portfolios and create jobs [11]. The cost-effectiveness of renewable energies in the United States is subject to some different conditions. A lack of nationwide incentives like Germany's feed-in tariff and a declining Federal Incentive Tax Credit (ITC) makes solar installation's cost-effectiveness a complicated issue.

\section{California Cost-Effectiveness}

Energy and Environmental Economics Inc. (E3) prepared a cost-effectiveness analysis for the California Energy Commission in 2013. The analysis was used to determine when the PV rooftop installations would be useful or cost-effective. The research focused on newly constructed or planned buildings between 2014 and 2020 that could incorporate rooftop PV for a 25 years of lifespan. The 25 year period is the industry standard warranty on PV cells. The study makes some assumptions to allow for estimates of cost and benefit. By extrapolating historic trends in PV, capital costs are assumed to decrease and efficiency to increase overtime. Electric retail rates are also expected to follow historic trends and increase over time. The scale of PV installations was assumed to be less than 10 kilowatt (KW) for residential rooftop and 10-100 KW for commercial buildings. The installations were also assumed to only occupy roof-space and not ground-space. The research selected several climate zones throughout California. A key assumption is that the analysis would not include state credit or monetary incentives for complying with the State's mandates or Renewable Portfolio Standards (RPS), this also excludes the declining Federal ITC of roughly $30 \%$. The E3 study concluded that rooftop PV was costeffective across the board for the average consumer. However, small scale residential installations were not cost effective below $5000 \mathrm{KWh}$ and large scale commercial was not cost effective in most climate zones [12].

\section{Renewable energy and STEM}

Even though there has been much debate about the existence of a shortage of future workers in STEM, America will need more engineers with advanced skill sets to address $21^{\text {st }}$ century needs of engineering industries, such as construction, environmental, automobile, energy and information technology. The renewable energy is one of the areas where lot of engineers and scientists are going to be in demand. In academia, a lot of emphasis should be given on including the aspects of renewable energy into the curriculum.

In many ways, the solar, wind and water related energy sectors will be affected if the shortage of workforce is not addressed soon. Therefore, it can be argued that if the issue of shortage of STEM workers is not addressed now, then it is going to be very difficult when each state attempts to satisfy the energy needs through $100 \%$ natural renewable energy sources such as solar, wind and water.

\section{Interpretation of Results}

The E3's findings can offer some insight into the usefulness of rooftop PV in Pennsylvania. Assuming that Pennsylvania has a greater average sunlight than many other states, we can conclude that the results only encourage the use of rooftop PV in Pennsylvania. The small scale 
installation threshold of $5000 \mathrm{KWh}$ for California could be applied to small scale Pennsylvania installations because of their comparable sun exposure. However, when considering the Federal ITCs, both the contended conditions approach cost-effectiveness.

\section{Conclusion}

It is undeniable that a change in power generation is necessary and imminent. The combined analysis of the various studies and interpreted data in this review shows that it is economically feasible and technologically possible to convert Pennsylvania to almost entirely renewable energy. The plan is also prudent way to reduce emissions and augment power capacity to meet growing demand. The ambitious Solutions Project plan for Pennsylvania does seem plausible. Some aspects of the Solutions Project did not match our data interpretations and may require alternative solutions and slightly different parameters. The importance of solar power PV and CSP cannot be understated when understanding the Solutions Project. The $75 \%$ solar power plan is both statistically possible and cost-effective in almost all utilities across Pennsylvania.

The results of the study show that it is possible to transition the state of conventional energy of Pennsylvania to renewable energy. The transition would create hundreds of thousands of initial jobs and require thousands of permanent operator jobs. It would also improve health conditions by vastly reducing pollutants like $\mathrm{CO}_{2}$ and sulfates. By also fostering a sense of sustainability and responsibility such a change would lower energy demand, reduce air pollution, and almost eliminate the state's reliance on fossil fuels. The Solutions Project [14] estimates that citizens could save roughly $\$ 2000$ dollars per year when the project is fully completed in 2050 .

\section{References}

[1] Natural Resources Defense Council. Pennsylvania. <http://www.nrdc.org/energy/renewables/Pennsylvania.asp>. Accessed February 11, 2017.

[2] U.S. Energy Information Administration. Pennsylvania State Profile and Energy Estimates. 〈http://www.eia.gov/state/data.cfm?sid=PA\#ReservesSupply>. Accessed February 11, 2017.

[3] Electric Rate for Residential buildings. <http://www.electricrate.com/ppl-electricrates/?a_aid=ppc\&gclid=CJr8leiJi9ICFU1LDQod7k8GeQ> Accessed February 12, 2017

[4] Center for Climate and Energy Solutions. Solar Power. 〈http://www.c2es.org/technology/factsheet/solar>. Accessed Nov. 1, 2016.

[5] Wilson, Robert. Reality Check: Germany Does Not Get Half of its Energy from Solar Panels, Aug. 14 ${ }^{\text {th }}$, 2014. <http://theenergycollective.com/robertwilson190/456961/reality-check-germany-does-not-get-halfits-energy-solar>. Accessed Oct. 28, 2016.

[6] Paidipati, J., Frantzis, L., Sawyer, H., and Kurrasch, A. Rooftop Photovoltaics Market Penetration Scenarios. <http://www.nrel.gov/docs/fy08osti/42306.pdf>. Accessed Nov. 1, 2016.

[7] Schwartz, Mark, Heimiller, Donna, Haymes, Steve, and Musial, Walt. NREL Assessment of Offshore Wind Energy Resources for the United States, June 2010. <http://www.nrel.gov/docs/fy10osti/45889.pdf>. Accessed Oct. 30, 2016.

[8] Masdar Corporate. <http://masdar.ae/en/\#masdar.> Accessed Nov 1, 2016.

[9] Future 360. Masdar City 2013. <http://future360.tv/video/masdar-city-2013>. Accessed Nov.1, 2016. 
[10] Wirth, Harry. Recent Facts about Photovoltaics in Germany, Oct 16 $6^{\text {th }}, 2016$. $<$ http://www.ise.fraunhofer.de/en/publications/veroeffentlichungen-pdf-dateien-en/studien-undkonzeptpapiere/recent-facts-about-photovoltaics-in-germany.pdf $>$. Accessed Nov. 1, 2016.

[11] Campbell, Corin. Solar energy prospects are bright for Scotland, experts say, May $19^{\text {th }} 2016$. <http://www.eurekalert.org/pub_releases/2014-05/uoe-sep051914.php>. Accessed Oct. 30, 2016.

[12] Pickrell, Katie, DeBenedictis, Andrew, Mahone Amber, and Price, Snuller. Cost-Effectiveness of Rooftop Photovoltaic Systems for Consideration in California's Building Energy Efficiency Standards, May 2013. <http://www.energy.ca.gov/2013publications/CEC-400-2013-005/CEC-400-2013-005-D.pdf>. Accessed Nov. 1, 2016.

[13] 100\% Pennsylvania : http://thesolutionsproject.org/infographic/\#pa Accessed November 1, 2016.

[14] The solutions Project: http://thesolutionsproject.org/ Accessed on November 1, 2016.

[15] Commonwealth Economics, "Energy in Pennsylvania : Past, Present and Future," a report submitted to Commonwealth of Pennsylvania, Department of Environmental Protection February 4, 2013. 